\title{
Inter and Intra Varietal Variation in Textural Characteristics of Carrots-a Standard Food in Chewing Studies
}

\author{
Rosie Morrell and Andrew J Rosenthal* \\ University of Nottingham, School of Biosciences, $U K$
}

*Corresponding author: Andrew J Rosenthal, University of Nottingham, School of Biosciences, Sutton Bonington, LE12 5RD, UK.

Received Date: July 05, 2019

Published Date: July 24, 2019

\begin{abstract}
Carrots have been widely used as a model food in chewing studies yet inter and intra varietal variation have not been considered, treating them as a standard material whose rheological and breakdown characteristics are constant. Using a texture analyzer, we determined small strain compression (Young's) moduli of carrot cores. We also undertook high speed, high strain compression tests to mimic the type of forces involved in chewing studies. Results suggest that for fresh carrots there is no significant difference between the textural characteristics of carrot varieties studied. Moreover, no difference exists in textural characteristics of sample cores obtained from different locations within the same carrot. As carrots are stored at temperatures between 10 and $30^{\circ} \mathrm{C}$ the Young's modulus declines exponentially with time, while the breaking stress gradually increases. Our data does suggest that the many researchers who have used carrots as consistent model food is justified in doing so as long as the produce is fresh.
\end{abstract}

Keywords: Mastication; Accelerated storage; Youngs modulus; Fracture; Particle breakdown

\section{Introduction}

Studies on the chewing, size reduction and oral processing of foods have invariably focused on three solid food materials. These materials are: Optosil ${ }^{\circledR}$ a polymer based dental resin; peanuts and carrots [1-5]. Variation in the physical properties of Optosil ${ }^{\circledR}$ is carefully controlled through process control during manufacturing. The breakdown characteristics and oral processing of peanuts and the effect of roasting have been previously reviewed [6], however, natural variation in the textural characteristics of the carrots have not been reported.

\section{Materials and Methods}

\section{Sample preparation}

Two varieties of carrot (Nairobi and Chantenay) were purchased from a local supermarket. All carrots were stored at 4 ${ }^{\circ} \mathrm{C}$ after purchase. In the case of the Nairobi carrots, $10 \mathrm{~mm}$ cores were cut from the top (approximately $15 \mathrm{~mm}$ from the top), middle and bottom. These cylindrical cores were trimmed with a razor to produce parallel ends. The shorter Chantenay carrots were only sampled from the top (approximately $15 \mathrm{~mm}$ from the top). In addition to the $4{ }^{\circ} \mathrm{C}$ stored carrots, an accelerated storage trial was undertaken, in which the carrots were stored at 10,20 and $30{ }^{\circ} \mathrm{C}$ for two weeks.

\section{Mechanical measurements}

A TA.HDplus texture analyzer (Stable Micro Systems, Godalming, UK) with a $100 \mathrm{~kg}$ load cell and $20 \mathrm{~mm}$ diameter flat ended probe was used. A two-bite procedure was developed:

1. The first, low strain bite, intended to measure the Young's modulus. With the carrot cylinder standing on end, the probe was brought into contact with its top, the sample height recorded. The sample was then compressed to $95 \%$ of its original height at $0.01 \mathrm{mms}^{-1}$. The strain was then relaxed and,

2. The second, high strain bite was intended to mimic mastication. The carrot core was compressed to $30 \%$ its original length, at a speed of $40 \mathrm{mms}^{-1}$. 


\section{Experimental protocols}

In addition to measurements of samples stored at $4{ }^{\circ} \mathrm{C}$, we undertook accelerated storage trials over a two-week period during which time the carrots were stored at 10,20 and $30{ }^{\circ} \mathrm{C}$.

\section{Results and Discussion}

The authors could only find one report of the Young's modulus of carrots in the literature, being around $3 \times 10^{7} \mathrm{~Pa}$ [7] which is of a similar magnitude to those reported in (Table 1). There is no significant difference between the Young's modulus values along the length of the Nairobi carrots ( $p>0.05$ ). Moreover, no significant difference exists between the two varieties tested. Likewise, there is no significant difference between the compressive breaking stress between the two varieties of carrot or the positions along the length of the Nairobi carrot (Table 1). However, the storage trial tells us a different story. Figure 1 shows the change in Young's modulus with storage time at 10,20 and $30{ }^{\circ} \mathrm{C}$. Data was exponential and could be straightened with a log plot yielding best line regression coefficients of $\mathrm{R}^{2}{ }_{10}{ }^{\circ} \mathrm{C}=0.87, \mathrm{R}^{2}{ }_{20}{ }^{\circ} \mathrm{C}=0.92$ and $\mathrm{R}^{2}{ }_{30}{ }^{\circ} \mathrm{C}=0.97$. The gradients of these lines are $\mathrm{e}^{-0.20}, \mathrm{e}^{-0.30}$ and $\mathrm{e}^{-0.44}$ which describe the loss of Young's modulus with storage time. A useful guide to gauge this decline is the time it takes to reduce the modulus by $90 \%$ which is $5.5,8$ and 13 days for 30,20 and $10{ }^{\circ} \mathrm{C}$ respectively (Figure 1).

Table1: Average Young's Modulus and Breakage Stress for Carrots of Two Varieties Sampled at Different Locations Along the Root (Figures in Brackets Are Standard Deviation).

\begin{tabular}{|c|c|c|c|c|}
\hline Variety & Position & N & Modulus (kPa) & Breakage (kPa) \\
\hline Chantenay & Top & 39 & $6,480( \pm 1,983)$ & $14,797( \pm 3,902)$ \\
\hline \multirow{3}{*}{ Nairobi } & Top & 39 & $7,966( \pm 5,098)$ & $13,997( \pm 7,184)$ \\
\cline { 2 - 5 } & Middle & 25 & $7,337( \pm 2,058)$ & $16,014( \pm 7,417)$ \\
\cline { 2 - 5 } & Bottom & 17 & $8,313( \pm 1,898)$ & $18,035( \pm 6,363)$ \\
\hline
\end{tabular}

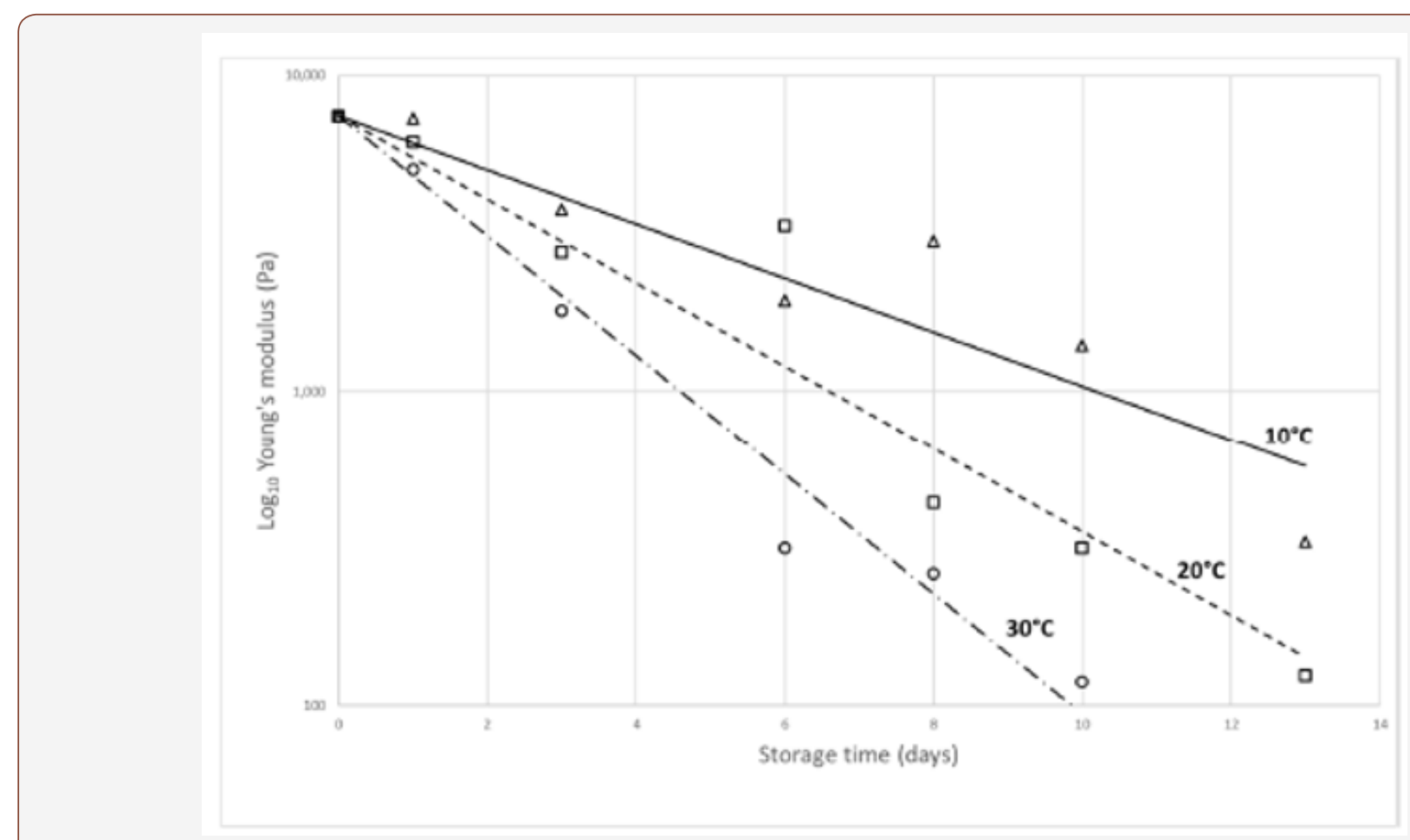

Figure 1: Effect of Storage Temperature on Young's Modulus of Carrots.

The effect of storage on the breaking stress is less obvious due partly to the scatter in the data (the regression coefficient for each temperature of storage being only about 0.45 ). Despite these all three storages temperatures show a slight linear increase in breaking stress with gradients in the region of 90Pa per day of storage. This increase in toughness is in keeping with Atkins and Vincent who found that the cutting forces required for flacid carrots was higher than when fully turgid [8].

\section{Acknowledgement}

None.

\section{Conflict of Interest}

No conflict of interest.

\section{References}

1. Lucas PW, Luke DA, Voon FC, Chew CL, OW R (1986) Food breakdown patterns produced by human subjects possessing artificial and natural teeth. J Oral Rehabil 13: 205-214.

2. Agrawal KR, Lucas PW, Prinz JF, Bruce IC (1997) Mechanical properties of foods responsible for resisting food breakdown in the human mouth. Arch Oral Biol 42: 1-9.

3. Fontijn Tekamp FA, Van Der Bilt A, Abbink JH, Bosman F (2004) Swallowing threshold and masticatory performance in dentate adults. Physiol Behav 83: 431-436.

4. Vincent JFW (2004) Application of fracture mechanics to the texture of food. Engineering Failure Analysis 11: 695-704.

5. Jalabert Malbos ML, Mishellany Dutour A, Woda A, Peyron MA (2007) Particle size distribution in the food bolus after mastication of natural foods. Food Quality and Preference 18: 803-812. 
6. Rosenthal AJ (2016) Textural aspects of peanuts and peanut products. In: Palmer R (edt.), Peanuts: Consumption, Allergies and Nutritional Content. Hauppauge, USA.

7. Finney EE (1973) Elementary concepts of rheology relevant to food texture studies, Dordrecht: D Reidel.
8. Prinz JF, Lucas PW (1997) An optimization model for mastication and swallowing in mammals. Proc Biol Sci 264: 1715-1721. 